\title{
Update on different aspects of HCV variability: focus on NS5B polymerase
}

\author{
Nadia Marascio ${ }^{1}$, Carlo Torti ${ }^{2,3}$, Maria Carla Liberto ${ }^{*}$, Alfredo Focà ${ }^{1}$ \\ From Third Workshop of the HCV Study Group in the Calabria Region \\ Catanzaro, Italy. 04 October 2013
}

\begin{abstract}
The study of hepatitis $\mathrm{C}$ virus (HCV) genotypes/subtypes, quasispecies and recombinants obtained by virus genome sequencing are important for epidemiological studies, to trace the source of infection, for development of new direct acting antivirals (DAAs) therapy and for understanding antiviral selection pressures. The HCV NS5B gene encodes a polymerase, which is responsible for virus replication and is a potential target for the development of antiviral agents. Many studies for classification of HCV use a particular segment of the NS5B gene, in addition to other specific regions, and phylogenetic analysis. Actually, some nucleoside/nucleotide analogues and nonnucleoside inhibitors target NS5B protein. This review focuses on HCV variability, phylogenetic analysis and the role of NS5B in the virus-host interactions.
\end{abstract}

\section{Introduction}

Hepatitis $\mathrm{C}$ virus (HCV) is classified as the type member of the genus Hepacivirus within the family Flaviviridae $[1,2]$. Nucleotide sequencing allows us to classify HCV into seven genotypes and many subtypes, epidemiologically related to risk factors and geographical areas [3].

$\mathrm{HCV}$ genotype determines the duration of antiviral therapy and predicts the response to treatment [4]. In particular viral genotypes influence clinical outcome not only to interferon (IFN)-based therapies but also to IFN free regimens. Classification of $\mathrm{HCV}$ into genotypes and subtypes detected by commercial assays is commonly satisfactory to reach a clinical choice. Moreover, the typing of $\mathrm{HCV}$ variants, as well as knowledge of the genetic diversity, is important for epidemiological studies such as those to trace the source of infection [5,6].

Phylogenetic and phylogeographical analysis have recently been applied to study the molecular epidemiology of HCV [7-9]. Interestingly, investigation of the spatial and temporal distribution of HCV diversity is critical not only to provide information on the virus origin and history, unknown prior to its identification, but

\footnotetext{
* Correspondence: mliberto@unicz.it

'Institute of Microbiology, Department of Health Sciences, "Magna Graecia" University of Catanzaro, Catanzaro, Italy

Full list of author information is available at the end of the article
}

also for understanding mechanism of virus-host interaction, and for preventive strategies [10,3].

Several studies reported heterogeneity in the regions sequenced along the HCV genome, such as 5'-UTR, core, NS5B, HVR-1, E2 and a segment of the NS5A gene associated with interferon sensitivity (ISDR) [11]. Guidelines for classification of genotypes/subtypes, using either the entire genome or the core/E1 and NS5B regions of $\mathrm{HCV}$ have been proposed [12,2]. In particular, a segment of the NS5B gene, identifying genomic polymorphisms, has been used [12,2]. HCV NS5B, an RNA dependent RNA polymerase (RdRp), has been studied in various biochemical assays, cell based assays and animal model systems. NS5B variability could be associated with a worse prognosis of the disease, as demonstrated for D310N substitution in HCV 3a infected patients [13].

The aim of the present review is to present the current knowledge of $\mathrm{HCV}$ variability for the critical role of NS5B in virus-host interaction.

\section{NS5B polymerase \\ Virological aspects}

The viral polymerase NS5B (full-length protein 591 amino acids, $a$ a) synthesizes a complementary negative strand RNA using as template genomic positive strand RNA. The 
catalytic domain, formed by $\mathrm{N}$-terminal 530 aa, exhibits the classical "fingers", "palm" and "thumb" subdomains typically seen in all RNA dependent RNA polymerases. The active site of NS5B is fully encircled by the fingers and thumb domains, which closely interact. All regular structures, studied until now, reveal a closed conformation, encircled on one side by the fingertips and on the other side by the linker and the so-called $\beta$-hairpin. Therefore, the active site is fully enclosed and the nucleotide molecules can bind easily with no further rearrangement of the domains $[14,15]$. As observed in in vitro studies, NS5B is able to conduct a template-directed RNA synthesis on its own, requiring only divalent metals (magnesium or manganese) as cofactors. NS5B can also catalyze both de novo synthesis from a single-stranded template and primer extension from the subsequent RNA duplex or from a pre-annealed template/primer duplex [16].

HCV RNA replicates in close association with intracellular membranes, so infected cells contain vesicles forming a membranous web (MW) that can be the $\mathrm{HCV}$ replication site [17].

Romero-Brey et al. [18], in 2012, carried out an investigation on the 3D morphology and biogenesis of the intracellular membrane structures induced by $\mathrm{HCV}$. The architecture of the membrane alterations induced by $\mathrm{HCV}$ reveals unexpected similarities between $\mathrm{HCV}$ and the unrelated picorna- and coronaviruses. Therefore, $\mathrm{HCV}$ induces, early during an infection, double membrane vesicles (DMVs), which emerge as protrusions of the endoplasmic reticulum (ER). Later on, HCV triggers multi-membrane vesicles (MMVs) that are probably the result of a cellular stress reaction [18]. Consequently, morphology of the MW depends not only on RNA replication, but also on activity of the nonstructural proteins NS3- NS5B, in concert with cellular factors [15]. Indeed, host factors such as lipid kinase phosphatidylinositol 4-kinase III alpha (PI4KIII $\alpha$ ) are essential for RNA replication and interact with NS5B and NS5A proteins. Silencing of PI4KIII $\alpha$ reduces vesicles formation, suggesting that this enzyme is critically involved in web morphology and consequently in viral replication $[19,20]$.

\section{Pathogenetical aspects}

NS5B binds to several cellular proteins. In particular, it directly interacts with $\mathrm{pRb}$ (retinoblastoma - susceptibility protein). The pRb-binding site of NS5B partially overlaps with its polymerase active site and then $R d R p$ activity is blocked. Interaction occurs in both replicon and $\mathrm{HCV}$-infected cells and induces ubiquitination and subsequent degradation of $\mathrm{pRb}$, probably contributing to the oncogenic property of HCV [21].

Liver cirrhosis and hepatocellular carcinoma induced by HCV may involve the interplay of different host cell factors, as well as interaction of these factors with viral RNA and proteins. Upadhyay et al. [22], using an affinity capture system in conjunction with liquid chromatography coupled with tandem mass spectrometry (LC-MS/MS), showed that three viral proteins, NS5B, NS5A and NS3/ 4A helicase are associated with replicating positive strand RNA genome in hepatoma cells. Moreover, 83 cellular factors such as translation factors, ribosomal proteins, and metabolic enzymes have been found to be associated with HCV genomic RNA. In particular the chaperonin T-complex polypeptide (TCP1), participates in HCV RNA replication and virion production, possibly through its interaction with NS5B. Moreover Caprin 1, a cell-cycle associated phosphoprotein, forms a complex with RasGTPase-activating protein-binding protein 1 (G3BP1) which has been shown to interact with both HCV NS5B and the 5 ' end of the HCV minus-strand RNA indicating that it is part of HCV replication complex [22].

In vitro models are important to study viral functional adaptation in human hosts and the natural course of infection [23]. An improvement was achieved after the cloning of a genotype 2a isolates from a Japanese patient with fulminant hepatitis (JFH 1 strain). Intra- and inter-genotypic chimeras, derived from the JFH1 strain, have also been constructed, allowing comparative studies between different genotypes/subtypes [24].

Characterization of JFH1 chimeric genome suggested a role for NS5B during viral assembly [25]. Authors generated a JFH1 chimeric genome, encoding an amantadinesensitive $\mathrm{p} 7$ protein, and identified two point mutations in NS2 and NS5B, which restored the infectivity of defective chimeric genomes. This finding disclosed an association among NS2, NS5B and p7 during virus morphogenesis [25].

\section{Therapeutical aspects}

NS5B represented, over the past decade, a therapeutic target for the inhibition of viral replication. Indeed, the new findings on viral replication, as well as close correlation between viral and host factors, make, even now, the polymerase a good therapeutic target. In addition, two first approved protease inhibitors show a low genetic barrier, inducing rapid onset of drug resistance. Actually, the resistance profiles of DAAs observed in clinical trials are strongly discussed.

Noteworthy alternative drugs are represented by nucleoside/nucleotide analogues, such as sofosbuvir, and nonnucleoside inhibitors, such as BI-207127, both of them directed to NS5B. Currently, sofosbuvir may be associated with ribavirin as therapy for HCV 2 or HCV 3 and with NS5A inhibitors for other genotypes. In HCV genotypes 1 and 4 infection, sofosbuvir/RBV/PEG-IFN may be given for 12 weeks. In persons with HCV 1 infection, IFN intolerant, sofosbuvir/RBV may be given for 24 weeks [26]. BI-207127 is in Phase III development in combination with ribavirin and an NS3 protease inhibitor [27]. 
Recently a replicon-based reagent suitable for convenient investigation of small molecule-mediated inhibition of $\mathrm{HCV}$ genotype 3 NS5A and NS5B has been generated and validated. This replicon chimera represents a useful tool to further study properties/behaviors of polymerase in different HCV genotypes [28].

\section{HCV variability}

\section{Virological aspects}

The positive strand of RNA genome is about 9600 nucleotides long and contains an open reading frame (ORF) encoding polyprotein precursor. The polyprotein is processed into structural and nonstructural proteins by host cell signal peptidases and two viral proteases (NS2 and NS3/4A) [14]. High HCV replication rate, such as $10^{12}$ virions per day, and the absence of proofreading activity of NS5B polymerase are the main factors that contribute to mutations in the viral genome. Genome variation is characterized by close genetic diversity among the viruses circulating in an infected host. As a result, HCV exists as a quasispecies [29]. $\mathrm{HCV}$ polymerase NS5B is responsible of the error mechanism of the gene products. In agreement with its functional role during the viral life cycle, there are few data on diversity within the HCV polymerase.

Recombination, which is an important evolutionary process, is uncommon during the $\mathrm{HCV}$ life cycle, although HCV type co-infections are recognized and recombination among genotypes would be expected [30]. Viral recombination has been demonstrated during HCV infection [31] and recently re-examined [32] in view of the low probability to detect recombinant strains and considering the potential underestimation of their incidence.

Viral variants have an impact on immunologic escape and/or antiviral drug resistance and the latter is particularly important in the DAAs (direct acting antivirals) era, when drugs act directly on the specific viral protein. Di Maio et. al [33] analyzed the NS5B polymerase variability in circulating HCV genotypes/subtypes and its impact on the genetic barrier for the development of resistance to clinically relevant nucleoside inhibitors (NIs)/non-nucleoside inhibitors (NNIs).

\section{Pathogenetical aspects}

Blackard et al. [34] detected NS5B intrapatient variability by a greater median genetic distance in the HIV/ $\mathrm{HCV}$-coinfected women than in the HCV-monoinfected women. Since HCV RNA levels appear to be significantly increased during $\mathrm{HIV} / \mathrm{HCV}$ coinfection and HIV coinfection is associated with a reduced drug therapy response, authors conclude that HIV can affect NS5B variability. This is intriguing as this suggests the host immune system, compromised by HIV, can influence genetic diversity of HCV. Functional characterization of unique NS5B sequences, identified in vivo, could demonstrate how NS5B variability influences viral replication fitness [34].

\section{Therapeutical aspects}

The effect of NS5B heterogeneity on the activity of nucleoside and non-nucleoside HCV polymerase inhibitors was investigated in clinical isolates obtained from serum samples of treatment-naive patients. It has been shown that non- nucleos(t)ide resistance mutations are present in the viral population at a low frequency in their quasispecies and these variants can be promptly selected upon drug pressure [35]. In particular, three major NNI resistant variants $(414 \mathrm{~T}, 419 \mathrm{~S}$, and $422 \mathrm{~K})$ were associated with a different genetic barrier score development among the six HCV genotypes. HCV NS5B sequencing could help to provide efficacy of NNI-containing regimens [33]. Blackard et al. [34] assessed serum NS5B variability in a subset of genotype 1-infected women, which included both $\mathrm{HIV} / \mathrm{HCV}$ coinfected and HCV monoinfected patients, demonstrated a link between NS5B viral diversity and viral load that could influence therapy outcomes. Among the partial NS5B consensus sequences generated, 21 of $114(18.4 \%)$ amino acid positions were variable. Moreover, recombination could implement antiviral resistances because two different mutations could be brought together a viral recombination event [32].

\section{Phylogenetic analysis Epidemiological aspects}

The epidemiology of HCV infection is rapidly changing and $\mathrm{HCV}$ prevalence rates between and within countries is characterized by local variability. Risk factors and genotype distribution also have significant geographic and temporal differences. Sequence variability analysis is important for molecular epidemiological studies and for understanding the endemic or epidemic origin of $\mathrm{HCV}$ infection. Furthermore, HCV epidemic subtypes show high prevalence, low genetic diversity, and spreading during the $20^{\text {th }}$ century via blood transfusions, injecting drug use and invasive medical procedures. On the contrary, endemic subtypes reveal long persistence in human populations in geographically restricted areas, with low transmission rates and a high genetic diversity as a result [36-38].

Epidemiological changes of HCV infection in Europe, such as in Italy, have been identified. In particular, human migration was responsible for early genotypes/ subtypes distribution and actually remains an important factor in HCV type spreading [39].

In 2012, our group investigated the phylogeny of $\mathrm{HCV}$ subtype $4 \mathrm{~d}$ isolated from Italian patients in Calabria (Southern Italy) by analyzing a fragment of the NS5B 
viral genomic region. A Bayesian coalescent-based framework was used to assess origin and spread of the HCV 4d in this area. Phylogenetic analysis indicated that genotype 4 circulated in Calabria region with a predominance of subtype $4 \mathrm{~d}$. Moreover, the Italian $4 \mathrm{~d}$ isolates shared a common ancestor with reference 4d isolates whose origin was traced back to 1940s (1913-1968). This finding suggests that spread of genotype $4 \mathrm{~d}$ probably began during the Second World War by immigration from Africa [8].

To assign an accurate genotype/subtype and to identify a new type, sequences of NS5B genomic region and phylogenetic analysis that reconstructed $\mathrm{HCV}$ spreading are required $[40,5]$.

In 2002, Richter reported that the NS5B region is the "gold standard" for accurate subtyping [41]. In the same year, Kalinina et al. isolated the first recombinant $\mathrm{HCV}$ strain. These authors identified an inter-genotype recombinant between a subtype $2 \mathrm{k}$ and a subtype $1 \mathrm{~b}$. In this study, the recombinant forms (RFs) were detected performing phylogenetic analysis on 5' UTR-core and NS5B regions [31].

$\mathrm{Du}$ et al. [42] detected firstly HCV 3a/1b recombinant through discrepancy of core/E2 and NS5B fragments sequences. HCV recombination and dual infection are often associated with high-risk multiple exposure behaviors. Detection of $3 \mathrm{a} / 1 \mathrm{~b}$ dual infection not only supports the existence of $\mathrm{HCV} 3 \mathrm{a} / 1 \mathrm{~b}$ recombinant, but also indicates a possibility of on-going generation of $\mathrm{HCV}$ inter-subtype recombinants [42].

\section{Pathogenetical aspects}

Genetic characterization of animal homologs of human viruses gives information on HCV natural history, evolution and preventive and therapeutic interventions. Kapoor et al. [10], reported the significant finding of HCV homologous non-primate virus. Phylogenetic analysis of conserved regions in NS3 and NS5B genes of rodent virus demonstrated homologous sequences with human viruses. The homology allows to hypothesize a zoonotic source of infection and suggests development of new animal models useful to investigate HCV pathogenesis and treatment. In particular, comparative genetic analysis and functional characterization studies might reveal host specificity determinants and different tissue tropism [10]. Extrahepatic replication of HCV in peripheral blood mononuclear cells (PBMC) has significant implications for disease progression and treatment outcome. However, few data are available concerning $\mathrm{HCV}$ variability in extrahepatic sites. Blackard et al. [43], by phylogenetic analysis of NS5B and E1/HVR1 sequences, evaluated quasispecies extrahepatic diversity by assessing NS5B variability in serum and PBMC samples from chronic HCV patients. Moreover, they identified the possible compartmentalization in PBMCs of $\mathrm{HCV}$ variants. Adaptive evolution of non-structural genomic regions such as NS5B could contribute to HCV persistence [43].

\section{Therapeutical aspects}

Pickett et al. [44], in 2011, identified a statistically significant evolutionary divergence of subtype $1 \mathrm{a} \mathrm{HCV}$ isolates into two distinct clades with potentially different phenotypic behaviors that may reflect differences in treatment response. The informative sites distinguishing clade 1 from clade 2 are distributed throughout the genome, but are mainly located in the E1, E2, NS2, NS5A, and NS5B coding regions. In particular, one site within the $5^{\prime}$ UTR and several sites within the NS5B genotyping fragments differ between clades 1 and 2, this information could be helpful to known if clades differ for therapy resistance. Furthermore, several variants are located at codons associated with resistance to protease inhibitors (NS3 Q41) or polymerase inhibitors (NS5B S368) [44].

\section{Conclusions}

Since HCV was isolated, there has been an increase in the number of studies to analyze the virus.

Structural and functional studies of the Hepatitis C virus RNA dependent RNA polymerase have contributed to our understanding of polymerase mechanism, viral RNA replication, and have generated targets for antiviral development. A multidisciplinary approach which could yield significant benefits to society against a disease with enormous worldwide impact is necessary. Major advances and future research questions on NS5B polymerase are reported in Table 1.

Nucleotide sequencing with phylogenetic analysis of NS5B genomic region, in addition to core/E1, is recommended for HCV genotyping [2]. Interestingly, the discrepancy of genotyping results between core/E2 and $\mathrm{NS} 5 \mathrm{~B}$ regions, indicates the presence of a $\mathrm{HCV}$ intersubtype recombinant [42].

NS5B region alone may be ineffective to identify $\mathrm{HCV}$ recombinants. The heterogeneity of the sequencing regions, in different publications, suggests a necessary standardization of regions analyzed for phylogenetics, phylodynamics and evolutionary studies.

Moreover, viral protein NS5B is a target for therapeutic intervention. The DAA molecules, either alone or in combination with peg-IFN plus RBV, were recently described as showing large antiviral effects. DAA monotherapy results in rapid emergence of resistant strains and DAAs must be used in combinations. The goal of the future studies will be to generate wild type and mutant (intra or inter-genotypes) replicons to investigate emergence and fitness of resistance for NS5B inhibitors. 


\section{Table 1 NS5B polymerase advances and future research}

\section{Major advances}

- NS5B interacts with different host factors for viral replication [14-20] and virus morphogenesis [25].

- NS5B represents a therapeutic target for the inhibition of viral replication $[27,35,44]$.

- NS5B is responsible for high variability of HCV [29].

- NS5B viral genomic region is necessary for phylogenetic and phylodinamic analysis [7-9], but not enough to identify recombinant strains $[31,32,42]$.

\section{Major research questions}

- Is NS5B variability associated with prognosis of the disease in HCV infected patients? [13]

- Is viral replication fitness influenced in HCV infected and HIV/HCV co-infected patients by NS5B variability? [34]

- Can adaptive evolution of NS5B contribute to persistence of HCV in PBMCs? [43]

\section{List of abbreviations used}

HCV: Hepatitis C virus; IFN: interferon; ISDR: interferon sensitivity; DAA s: direct acting antivirals; PBMC: peripheral blood mononuclear cells; HVR1: hypervariable region 1; JFH1: Japanese fulminant hepatitis strain; RFs: recombinant forms; TCP1: chaperonin T-complex polypeptide; G3BP1: RasGTPase-activating protein-binding protein 1.

\section{Competing interests}

The authors declare that they have no competing interests.

\section{Authors' contributions}

NM wrote the review article; $C T$ contributed to major review revision; $\mathrm{MCL}$ designed and wrote the review article; AF contributed to major review revision.

\section{Declarations}

Publication of this supplement was partly supported by an unrestricted grant provided by Roche. The articles were independently prepared by the authors with no input from Roche. Roche were not involved in selecting the articles for the supplement.

This article has been published as part of BMC Infectious Diseases Volume 14 Supplement 5, 2014: Proceedings of the Third Workshop of the HCV Study Group in the Calabria Region: Results from the South Italian Network for Rational Guidelines and International Epidemiology (SINERGIE) Project. The full contents of the supplement are available online at http://www. biomedcentral.com/bmcinfectdis/supplements/14/S5.

\section{Authors' details}

'Institute of Microbiology, Department of Health Sciences, "Magna Graecia" University of Catanzaro, Catanzaro, Italy. ${ }^{2} U n i t$ of Infectious Diseases, Department of Medical and Surgical Sciences, "Magna Graecia" University of Catanzaro, Catanzaro, Italy. ${ }^{3}$ University Unit of Infectious Diseases, University of Brescia, School of Medicine, Brescia, Italy.

Published: 5 September 2014

\section{References}

1. Simmonds P, Holmes E C, Cha TA, Chan SW, McOmish F, Irvine B, Beall E, Yap PL, Kolberg J, Urdea MS: Classification of hepatitis C virus into six major genotypes and a series of subtypes by phylogenetic analysis of the NS-5 region. J Gen Virol 1993, 74:2391-2399.

2. Simmonds P, Combet C, Deleage G, Enomoto N, Feinstone S, Halfon P, Inchauspe' $G$, Kuiken $C$, et al: Consensus proposals for a unified system of nomenclature of hepatitis C virus genotypes. Hepatology 2005, 42:962-973.

3. Simmonds $P$ : The origin of hepatitis $\mathbf{C}$ virus. Curr Top Microbiol Immunol 2013, 369:1-15.

4. European Association of the Study of the Liver: 2011 European Association of the Study of the Liver hepatitis C virus clinical practice guidelines. Liver Int 2012, 32(Suppl 1):2-8.

5. Pollicita M, Cento V, Paba P, Perno CF, Ciotti M: Nucleotide polymorphisms in the $5^{\prime}$-UTR region of HCV can affect the ability of two widely used assays to assign an HCV genotype. J Virol Methods 2013, 193(1):205-208,

6. González V, Gomes-Fernandes M, Bascuñana E, Casanovas S, Saludes V, Jordana-Lluch E, Matas L, Ausina V, Martró E: Accuracy of a commercially available assay for HCV genotyping and subtyping in the clinical practice. J Clin Virol 2013, 58(1):249-253.

7. Lampe E, Lewis-Ximenez L, Espírito-Santo MP, Delvaux NM, Pereira SA, Peres-da-Silva A, Martins RM, Soares MA, Santos AF, Vidal LL, Germano FN, de Martinez AM, Basso R, Pinho JR, Malta FM, Gomes-Gouvêa M, Moliterno RA, Bertolini DA, Fujishima MA, Bello G: Genetic diversity of HCV in Brazil. Antivir Ther 2013, 18(3 Pt B):435-444.

8. Ciccozzi M, Equestre M, Costantino A, Marascio N, Quirino A, Lo Presti A, Cella E, Bruni R, Liberto MC, Focà A, Pisani G, Zehender G, Ciccaglione AR: Hepatitis $C$ virus genotype $4 d$ in Southern Italy: reconstruction of its origin and spread by a phylodynamic analysis. J Med Virol 2012, 84(10):1613-1619.

9. Re' VE, Culasso ACA, Mengarelli S, Farıas AA, Fay F, Pisano MB, Elbarcha O, Contigiani MS, Campos RH: Phylodynamics of Hepatitis C Virus Subtype 2c in the Province of Cordoba, Argentina. PLOS ONE 2011, 6(5):e19471.

10. Kapoor A, Simmonds P, Scheel TKH, Hjelle B, Cullen JM, Burbelo PD, Chauhan LV, Duraisamy R, Sanchez Leon M, Jain K, Vandegrift K, Calisher $\mathrm{CH}$, Rice $\mathrm{CM}$, Lipkin WI: Identification of rodent homologs of hepatitis C virus and pegiviruses. mBio 2013, 4(2):e00216-13.

11. Jacka B, Lamoury F, Simmonds P, Dore GJ, Grebely J, Applegate T: Sequencing of the Hepatitis C Virus: A Systematic Review. PLOS ONE 2013, 8(6):e67073.

12. Enomoto N, Takada A, Nakao T, Date T: There are two major types of hepatitis C virus in Japan. Biochem Biophys Res Commun 1990, 170(3):1021-1025.

13. Jaspe RC, Sulbarán YF, Sulbarán MZ, Loureiro CL, Rangel HR, Pujol FH: Prevalence of amino acid mutations in hepatitis $C$ virus core and NS5B regions among Venezuelan viral isolates and comparison with worldwide isolates. Virol J 2012, 9:214.

14. Moradpour D, Penin F: Hepatitis C virus proteins: from structure to function. Curr Top Microbiol Immunol 2013, 369:113-142.

15. Lohmann V: Hepatitis C virus RNA replication. Curr Top Microbiol Immunol 2013, 369:167-198.

16. Harrus D, Ahmed-El-Sayed N, Simister PC, Miller S, Triconnet M, Hagedorn CH, Mahias K, Rey FA, Astier-Gin T, Bressanelli S: Further insights into the roles of GTP and the $C$ terminus of the hepatitis $C$ virus polymerase in the initiation of RNA synthesis. J Biol Chem 2010, 285(43):32906-32918.

17. Ferraris $\mathrm{P}, \mathrm{Blanchard} \mathrm{E}$, Roingeard $\mathrm{P}:$ Ultrastructural and biochemical analyses of hepatitis $C$ virus-associated host cell membranes. J Gen Virol 2010, 91(Pt 9):2230-2237.

18. Romero-Brey I, Merz A, Chiramel A, Lee J-Y, Chlanda P, Haselman U, Santarella-Mellwig R, Habermann A, Hoppe S, Kallis S, Walther P, Antony C, Krijnse-Locker J, Bartenschlager R: Three-Dimensional Architecture and Biogenesis of Membrane Structures Associated with Hepatitis C Virus Replication. PLoS Pathog 2012, 8(12):e1003056.

19. Reiss S, Rebhan I, Backes P, Romero-Brey I, Erfle H, Matula P, Kaderali L, Poenisch M, Blankenburg H, Hiet MS, Longerich T, Diehl S, Ramirez F, Balla T, Rohr K, Kaul A, Bühler S, Pepperkok R, Lengauer T, Albrecht M, Eils R, Schirmacher P, Lohmann V, and Bartenschlager R: Recruitment and activation of a lipid kinase by hepatitis C virus NS5A is essential for integrity of the membranous replication compartment. Cell Host Microbe 2011, 9(1):32-45.

20. Berger KL, Kelly SM, Jordan TX, Tartell MA, and Randall G: Hepatitis C Virus Stimulates the Phosphatidylinositol 4-Kinase III Alpha-Dependent 
Phosphatidylinositol 4-Phosphate Production That Is Essential for Its Replication. J Virol 2011, 85:8870-8883.

21. Tang H, Grisé H: Cellular and molecular biology of HCV infection and hepatitis. Clin Sci (Lond) 2009, 117(2):49-65.

22. Upadhyay A, Dixit U, Manvar D, Chaturvedi N, Pandey VN: Affinity capture and identification of host cell factors associated with hepatitis $C$ virus (+) strand subgenomic RNA. Mol Cell Proteomics 2013, 12(6):1539-1552.

23. Steinmann E, Pietschmann T: Cell culture systems for hepatitis $C$ virus. Curr Top Microbiol Immunol 2013, 369:17-48.

24. Wahyuni TS, Tumewu L, Permanasari AA, Apriani E, Adianti M, Rahman A, Widyawaruyanti A, Lusida MI, Fuad A, Soetjipto D, Nasronudin D,

Fuchino H, Kawahara N, Shoji I, Deng L, Aoki C, Hotta H: Antiviral activities of Indonesian medicinal plants in the East Java region against hepatitis C virus. Virol I 2013, 10(1):259.

25. Gouklani H, Bull RA, Beyer C, Coulibaly F, Gowans EJ, Drummer HE, Netter HJ, White PA, Haqshenas G: Hepatitis C virus nonstructural protein 5B is involved in virus morphogenesis. J Virol 2012, 86(9):5080-5088.

26. World Health Organization: Guidelines for the screening, care and treatment of persons with hepatitis C infection. 2014 [www.who.int].

27. Soriano V, Vispo E, de Mendoza C, Labarga P, Fernandez-Montero JV, Poveda E, Treviño A, Barreiro P: Hepatitis C therapy with HCV NS5B polymerase inhibitors. Expert Opin Pharmacother 2013, 14(9):1161-1170.

28. Kylefjord H, Danielsson A, Sedig S, Belda O, Wiktelius D, Vrang L, TargettAdams P: Transient replication of a hepatitis $C$ virus genotype $1 \mathrm{~b}$ replicon chimera encoding NS5A-5B from genotype 3a. J Virol Methods 2013.

29. Figlerowicz $M$, Jackowiak $P$, Formanowicz $P$, Kedziora $P$, Alejska $M$, Malinowska N, Błazewicz J, Figlerowicz M: Hepatitis C virus quasispecies in chronically infected children subjected to interferon-ribavirin therapy. Arch Virol 2010, 155:1977-1987.

30. Shi W, Freitas IT, Zhu C, Zheng W, Hall WW, Higgins DG: Recombination in Hepatitis C Virus: Identification of Four Novel Naturally Occurring InterSubtype Recombinants. PLOS ONE 2012, 7(7):e41997.

31. Kalinina $\mathrm{O}$, Norder H, Mukomolov S, Magnius LO: A natural intergenotypic recombinant of hepatitis C virus identified in St. Petersburg. J Virol 2002, 76(8):4034-4043.

32. González-Candelas F, López-Labrador FX, Bracho MA: Recombination in Hepatitis C Virus. Viruses 2011, 3:2006-2024.

33. Di Maio VC, Cento V, Mirabelli C, Artese A, Costa G, Alcaro S, Perno CF, Ceccherini-Silberstein F: Hepatitis C Virus Genetic Variability and the Presence of NS5B Resistance-Associated Mutations as Natural Polymorphisms in Selected Genotypes Could Affect the Response to NS5B Inhibitors. Antimicrob Agents Chemother 2014, 58(5):2781-2797.

34. Blackard JT, Ma G, Limketkai BN, Welge JA, Dryer PD, Martin CM, Hiasa Y, Taylor LE, Mayer KH, Jamieson DJ, Sherman KE: Variability of the polymerase gene (NS5B) in hepatitis C virus-infected women. J Clin Microbiol 2010, 48(11):4256-4259.

35. Le Pogam S, Seshaadri A, Kosaka A, Chiu S, Kang H, Hu S, Rajyaguru S, Symons J, Cammack N, and Najera I: Existence of hepatitis C virus NS5B variants naturally resistant to non-nucleoside, but not to nucleoside, polymerase inhibitors among untreated patients. $J$ Antimicrob Chemother 2008, 61:1205-1216.

36. Markov PV, van de Laar TJ, Thomas XV, Aronson SJ, Weegink CJ, van den Berk GE, Prins M, Pybus OG, Schinkel J: Colonial history and contemporary transmission shape the genetic diversity of hepatitis $C$ virus genotype 2 in Amsterdam. J Virol 2012, 86(14):7677-7687.

37. Forbi JC, Purdy MA, Campo DS, Vaughan G, Dimitrova ZE, GanovaRaeva LM, Xia GL, Khudyakov YE: Epidemic history of hepatitis $C$ virus infection in two remote communities in Nigeria, West Africa. J Gen Virol 2012, 93(7):1410-1421.

38. Kchouk FH, Gorgi Y, Bouslama L, Sfar I, Ayari R, Khiri H, Halfon P, Aouadi H, Jendoubi Ayed S, Ayed K, Ben Abdallah T: Phylogenetic analysis of isolated HCV strains from tunisian hemodialysis patients. Viral Immunol 2013, 26(1):40-48.

39. Esteban Jl, Sauleda S, Quer J: The changing epidemiology of hepatitis C virus infection in Europe. J Hepatol 2008, 48(1):148-162.

40. Larrat S, Poveda JD, Coudret C, Fusillier K, Magnat N, Signori-Schmuck A, Thibault V, Morand P: Sequencing Assays for Failed Genotyping with the Versant Hepatitis C Virus Genotype Assay (LiPA), Version 2.0. J Clin Microbiol 2013, 51(9):2815-2821.
41. Richter SS: Laboratory assays for diagnosis and management of hepatitis C virus infection. J Clin Microbiol 2002, 40(12):4407-4412.

42. Du H, Qi Y, Hao F, Huang Y, Mao L, Ji S, Huang M, Qin C, Yan R, Zhu X, Zhang C: Complex patterns of HCV epidemic in Suzhou: evidence for dual infection and HCV recombination in East China. J Clin Virol 2012, 54(3):207-212.

43. Blackard JT, Ma G, Welge JA, Martin CM, Sherman KE, Taylor LE, Mayer KH, Jamieson DJ: Analysis of a non-structural gene reveals evidence of possible hepatitis C virus (HCV) compartmentalization. J Med Virol 2012, 84(2):242-252.

44. Pickett BE, Striker R, Lefkowitz EJ: Evidence for separation of HCV subtype 1a into two distinct clades. J Viral Hepat 2011, 18(9):608-618.

doi:10.1186/1471-2334-14-S5-S1

Cite this article as: Marascio et al:: Update on different aspects of HCV variability: focus on NS5B polymerase. BMC Infectious Diseases 201414 (Suppl 5):S1.

\section{Submit your next manuscript to BioMed Central and take full advantage of:}

- Convenient online submission

- Thorough peer review

- No space constraints or color figure charges

- Immediate publication on acceptance

- Inclusion in PubMed, CAS, Scopus and Google Scholar

- Research which is freely available for redistribution

Submit your manuscript at www.biomedcentral.com/submit
C Biomed Central 